This section includes shorter (e.g., 10-15 double-spaced manuscript pages or less) papers describing methods and techniques that can improve evaluation practice. Method notes may include reports of new evaluation tools, products, and/or services that are useful for practicing evaluators. Alternatively, they may describe new uses of existing tools. Also appropriate for this section are user-friendly guidelines for the proper use of conventional tools and methods, particularly for those that are commonly misused in practice.

\title{
The Potential of Social Capital Measures in the Evaluation of Comprehensive Community-Based Health Initiatives
}

\author{
DANA M. PETERSEN
}

\begin{abstract}
Determining the effectiveness of comprehensive community initiatives (CCIs) poses measurement challenges for evaluators and communities, especially those attempting to employ participatory evaluation. In light of the growing body of research documenting, a relationship between social capital and health, this paper suggests, first, that evaluators should consider social capital as one of the major influences in health and well-being and, second, that measures of social capital should receive increased attention as indicators of progress toward health outcome goals. In this note, I clarify what is meant by the concept "social capital," offer a possible operationalization of the term, present findings from a small sample of studies that demonstrate links between measures of social capital and health, and offer justification of this alternative measurement approach for the evaluation of CCIs. Discussion is based on SRI International's work with communities involved in the Sierra Health Foundation's community partnerships for healthy children initiative.
\end{abstract}

Dana M. Petersen • SRI International, BS 143-333 Ravenswood Ave, Menlo Park, CA 94025, USA; Tel: (1) 650-859-4518; E-mail: dana.petersen@sri.com. 


\section{INTRODUCTION}

In this paper, I explore the implications for the evaluation of CCIs of research findings on the health advantages stemming from social capital. CCIs are holistic in scope, are varied in process, and often take many years to show change related to community health outcomes. As a result, those engaged in community-based health evaluation face important and practical dilemmas. I suggest that evaluators working with large-scale CCIs build measures of social capital into existing evaluation methodologies. That is, I suggest that measures of social capital be used as interim short-term indicators of progress toward desired long-term goals. Measures of social capital supplement the examination of longer-term health outcomes and provide valuable interim measures.

\section{BACKGROUND: THE CPHC EVALUATION}

For the past 8 years, the Center for Education and Human Services at SRI International (SRI) has served as the evaluator of the Sierra Health Foundation's 10-year, >\$20 million effort to improve the health and well-being of young children in 26 northern California communities. The initiative, Community Partnerships for Healthy Children (CPHC), was launched in 1993 and is one of a new generation of CCIs designed to address pressing social problems in today's communities. CCIs of this generation attempt to solve a wide array of social problems with different focuses (e.g., housing, economic development, school improvement, or health and human services). In addition, contemporary CCIs share an appreciation of the interdependence of physical, economic, and social contexts and a desire to create synergy among them (Brown, 1996). CCIs seek to implement their approaches within a broad, holistic understanding of community change and improvement. And although the specific goals of CCIs can be described in many different ways, most comprehensive initiatives aim to strengthen the social fabric of the community or, in more academic terms, to build social capital.

The Sierra Health Foundation targets its comprehensive community initiative on improving the health and well-being of children from birth through age 8 , while specifically acknowledging the need to rebuild the social fabric of communities so they can support the desired outcome. Like other CCIs, the CPHC initiative is based on a community-building and empowerment paradigm. CPHC required communities to form local collaboratives that mobilize local residents, first, to identify the most challenging issues facing children and families in their communities and, second, to design strategic action plans and implement solutions to address these issues and achieve the goals of the initiative in their local areas. By fostering solutions at the community level, the foundation views this grant-making initiative as triggering changes in the way participating communities address children's health (see http://www.sierrahealth.org/programs/cphc.html). Several waves of communities were first funded for a 12-18 month community development phase, then for an 18 month program planning phase, followed by up to 3 years for implementation. In summer 2000, the CPHC initiative entered its fourth phase, the impact and sustainability phase.

As evaluator for the initiative, SRI worked with the Sierra Health Foundation to apply a "theory of change" approach to help the foundation define outcomes and processes that are intended to affect those outcomes (Weiss, 1995). This approach involved developing a priori hypotheses about how components of the initiative were to be implemented and, once implemented, how they were expected to result in improved outcomes. Next, SRI attempted to 
carefully document the extent to which the implementation and outcomes occurred. By bringing data to bear on each process, activity, assumption, and outcome specified in the theory, SRI began to test the plausibility of the links proposed in the theory of change. Fig. 1 is a simplified depiction of CPHC's theory of change. The left side of Fig. 1 shows the key areas of resource concentration by the Sierra Health Foundation (grant making, capacity building, developing partnerships, etc.). These serve as inputs to the initiative. Moving farther to the right in Fig. 1, one sees the representation of the work of the local community collaboratives. Two critical events are hypothesized to be occurring simultaneously and interactively in the local communities through the collaboratives' efforts: the strategies in each collaborative's action plan are being carried out, and social capital (i.e., social trust, responsibility, cooperation, and action) is being built. The enactment of the strategies enhances social capital in the community, and as more social capital is built, more resources become available to carry out strategies successfully. Thus, Fig. 1 shows a synergistic relationship between the strategies being carried out and the development of social capital. The hypothesized result of this synergy is an improvement in one or more community outcomes.

Examples of community outcomes include the development of informal support systems, improved access to information, improved and expanded prevention services, and supportive and effective policies and systems. These improved community-level outcomes, the theory hypothesizes, will result in improved health and well-being for children, either directly or through the efforts of their families, who are also expected to experience improved health and well-being. Examples of child health outcomes include more children being immunized, reduced child abuse, reduced childhood asthma, and more children starting school ready to learn. Also included in the theory of change are external factors (national economy, state and federal policy, etc.) and community characteristics (social conditions, history of

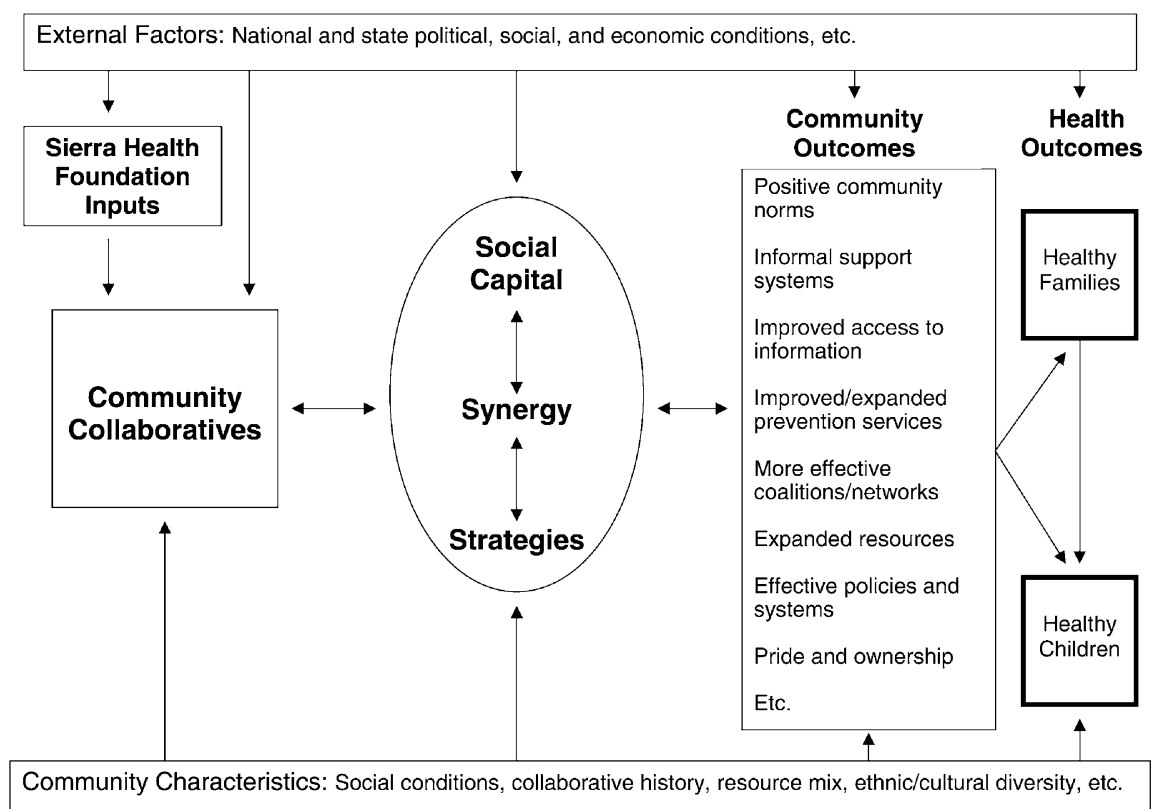

Figure 1. CPHC Theory of Change. 
collaborative activity, mix of community resources, ethnic/cultural diversity, etc.) that may also affect community collaboratives' implementation of strategies and building of social capital, and therefore progress toward desired outcomes. The precise nature of the link between social capital, the community-driven strategies, and health outcomes is unknown. SRI recognizes that the implementation of different strategies may enhance social capital in different ways and levels, and that health outcomes may be differentially affected by particular strategies, community characteristics, and external factors. SRI hopes that the CPHC evaluation, and others of similar CCIs, will help to specify and test these potential pathways and connections further.

\section{MEASUREMENT CHALLENGES IN EVALUATIONS OF CCIS}

Some of the methodological challenges SRI has encountered while evaluating CPHC are generic to most CCIs (Connell, Kubisch, Schorr, \& Weiss, 1995). The foundation's approach allowed individual communities to define for themselves the best means to improve child health in their local contexts, and each community identified its own target issue or issues. As can be expected, the local context, history, and culture of each place and its residents played a significant role, resulting in diversity among funded communities in the strategies they chose for building community and improving children's health. Some communities sponsored community gardens; some presented formal parent education or job training classes; others established pee wee sports programs; still others created full-service family resource centers. The $26 \mathrm{com}$ munities choose vastly different issues to work on as means to improving child health and implemented strategies to address these issues across multiple sectors-social (e.g., parenting classes), physical (e.g., pee wee sports), and economic (e.g., job training)—and multiple levels (targeting the child, family, and/or community). This process led to a broad range of outcomes to be tracked and measured in each of the 26 supported communities: a total 451 indicators in 22 outcome areas. In multi-site initiatives, even if all funded communities are given the same overall charge, it is still very common that strategies and individual program components vary significantly from place to place and evolve continually. The situation is exaggerated in this case because the Sierra Health Foundation's commitment to community-driven approaches allowed each community to identify its own health priority and action plan. This diversity dramatically increases tracking and data collection difficulty and comparability, especially within a participatory evaluation style, where communities are learning to collect and report data themselves. Although communities are responsible for identifying and collecting some outcome data on their own, the SRI evaluation team is responsible for tracking data on a common set of 26 statistical indicators for all collaborative communities involved in CPHC.

The most pressing evaluation dilemma faced by SRI in CPHC's final years is: how does one determine the effectiveness of a multi-year, multi-million dollar initiative to improve the health of children? Although some CCI evaluations, like SAMHSA's (2001) Center for Substance Abuse and Prevention's Community Partnership Study, have succeeded in collecting long-term health outcome data (related to substance abuse via interviews and surveys), many others have not (see http://www.health.org/govstudy/ms666/q\&a.htm). Health outcome data based on current individual behavior, such as substance use or abuse, may be easier and more reasonable to collect during the time frame of a CCI than are data on other health outcomes, such as the presence or lack of illness and disorders (e.g., cardiovascular disease, childhood asthma). Changes in measures of standard long-term health indicators may have lead times 
of up to 10 years, meaning that communities may appear to have achieved very little, if anything, for their efforts after only 3 years. Measuring impacts of local strategies on many types of long-term health outcomes is difficult for foundation-funded communities, given the short lives of the programs and strategies themselves, the limited evaluation training and resources of community members, the small target populations, and the lack of reliable health outcome indicator data for young children. Also, county- and state-level data do not fairly represent the impact or possible impact of strategies focused on a single town or neighborhood. In addition, community strategies are unlikely to produce changes in standard long-term health indicators during the short time of the initiative's strategy implementation phase (up to 3 years). As mentioned previously, foundation-funded communities are measuring progress toward self-identified long-term health outcomes, such as reduction in child abuse or asthma rates, or increases in percentages of children entering school ready to learn (while SRI tracks a set of common indicators across communities).

Given that some components of the CPHC evaluation design are participatory in nature (with SRI providing evaluation technical assistance) and given that communities are responsible for collecting and reporting their own outcome data, SRI has also had trouble keeping communities interested and on task. It is difficult to link changes in long-term health outcomes empirically to locally defined and implemented community strategies, such as pee wee sports or parent education. I have found that communities lose motivation to collect data that seem unrelated to their local activities, and that they are sometimes fearful that the data will not clearly demonstrate the success that they "know" they are experiencing. They are frustrated at being unable to document their felt successes effectively. Measures of social capital may be more intuitively linked to community involvement in collaborative strategies and better reflect the communities' own experiences.

Again, the dilemma is: how should SRI measure the actual and felt success of communities involved in the CPHC initiative? Clearly, a consensus on what constitutes appropriate measures for assessing the impact and effectiveness of large community-based initiatives such as CPHC is desperately needed among researchers, evaluators, funders, and service providers. In light of the growing body of research documenting a relationship between social capital and health, I suggest that social capital begin to be considered as one of the major influences in health and well-being and that measures of social capital receive attention as accepted indicators of progress toward health outcome goals. According to the CPHC theory of change, increases in the level of social capital in a given community indicate progress in the desired direction toward ultimate health outcomes. SRI acknowledges that child and family health are the ultimate desired outcomes of CPHC but, given the dilemmas of measurement and data collection discussed, I suggest focusing on the intermediate outcome of social capital as a legitimate measurement alternative. I suggest that measures of social capital be used as a short-term evaluation strategy, complementing standard measures of long-term health outcomes when attempting to determine community success. Again, this possibility is particularly relevant in the case of CPHC, where the sponsoring foundation views community building and the strengthening of social fabrics as both penultimate goals and critical mechanisms for improving health outcomes.

\section{THE NATURE OF SOCIAL CAPITAL}

SRI defines social capital in accordance with Putnam's basic and generally accepted definition. In his terms, social capital is the "glue that holds a community together." Social capital consists 
of those specific processes among people and organizations, working collaboratively in an atmosphere of trust, that lead to accomplishing a goal of mutual shared benefit (Putnam, 1993). It does not refer to individuals, but rather to the interactions among and between individuals through systems that enhance and support that interaction. Putnam suggests that the core elements of social capital are trust and cooperation and that these can be developed over time by repeated contact of people involved in long-term relationships that are supported by community institutions (Putnam, 1993). In the context of the CPHC evaluation, SRI goes a step farther, adding that social capital also implies an expectation, willingness, and ability to act based on those feelings of shared trust and cooperation. In other words, shared perceptions of trust and cooperation call community members into action, culminating in behaviors that are predictable and mutually beneficial.

Putnam's assertion that the core elements can be developed over time provides hope that social capital could be purposely created and fostered via social programs and communitybuilding initiatives, and provides support for the assumptions underlying CPHC's theory of change. Also supporting CPHC's theory of change is the idea that social capital has the potential to strengthen community social fabrics because it builds bonds based on information, trust, and solidarity among people, most often as by-products of their activities (Coleman, 1990).

There are competing perspectives on social capital, however. Part of the present ambiguity concerns whether social capital is defined in terms of its effects or in terms of its characteristics. Some view social capital as a causal or moderating variable. That is, they believe that levels of social capital in a particular community are given and that these levels influence the effectiveness of community building and organizing (Kreuter, 1998). If one takes an alternative perspective that social capital is a consequence or product, as in CPHC's theory of change, it is social capital that is influenced, promoted, and/or created according to levels of community building and collaboration. Another possible perspective is that both social capital and hypothesized health outcomes are consequences of yet other forces, such as external factors and/or community characteristics. Again, SRI hopes that the evaluation of CPHC will provide useful information to help decipher these differences in perspectives on causal relationships.

According to the working definition provided here, a community with high levels of social capital would be full of individuals who trust, know, and take care of each other while working toward the common good of the entire community (Easterling, Gallagher, Drisko, \& Johnson, 1998). It seems likely that such a community would foster high levels of health and well-being among its residents. In addition to the likely and theoretical links between social capital and health, there is a growing body of research empirically linking the two. For example, Kawachi, Kennedy, Lochner, and Prothrow-Smith (1997) found that measures of social capital (as measured by General Social Survey items for membership in voluntary groups and levels of social trust) were significantly related to measures of health status at the state level. They found that increases in the level of social trust and group membership were statistically associated with decreases in total mortality, as well as in rates of death from coronary heart disease, malignant neoplasms, and infant mortality. In another example, Runyan, Hunter, Socolar, Amaya-Jackson, English, Landsverk, Dubowitz, Browne, Bangdiwala, and Mathew (1998) found that high levels of social capital were associated with positive developmental and health outcomes for high-risk pre-school children. Along with the growing public health literature on the connection between social capital and health, considerable other research has used a broader array of terms to describe attributes of what is now often called social capital. Other terms describing attributes of social capital and found in the literature that can be linked to health outcomes include social support, sense of community, community capacity, collective 
efficacy, empowerment, and others (Bowles, 1999; Gardner, 1990; Lappe \& DuBois, 1997; LaVeist, 1992; Roberts, 1997; Sampson, Raudenbush, \& Earls, 1997). For example, studies examining social support have demonstrated links to health. Roberts (1997) found that the chances of having a low-weight birth tended to be lower for women living in communities with strong cooperative social networks. The contention that social capital relates to health outcomes also builds on a much larger body of research documenting the positive effects of relationship and community building on a wider definition of community health, including such things as the reduction of violence, crime, substance abuse, and teen pregnancy (Brendo, 1994; Sampson et al., 1997; Walsh, 1997).

Although there is some debate about the strength of the link between social capital and health, the emerging evidence is worthy of serious consideration and certainly indicates a need for further investigation. I also believe that many stakeholders see measures of social capital as legitimate indicators of enriched community lives. Using measures of social capital as short-term evaluation measures indicating progress toward desired long-term health outcomes may help to alleviate some of the problems of frustration and lack of engagement experienced among community members involved in participatory evaluation. As discussed previously, some community members do not see the effects of their efforts on-or the relationship of their efforts to-standard long-term health indicators. Changes in measures of social capital could have shorter lead times than other health indicators and could act as interim outcomes, coming before, and being followed by, slower-coming health outcome changes. Communities thus may be invigorated and motivated by effects that they can document in the short-term. It is also possible that social capital data could be collected specifically at the level of the population for which the health outcome was intended (e.g., town or neighborhood, rather than county or state). If evaluators should decide to include measures of social capital in their designs, it is important to determine indicators early in the project and to collect baseline measures as soon as possible. Although the lag time for change in social capital measures is often much shorter than for standard long-term health outcomes, most measures still need at least 3 years to show change.

\section{THE MEASUREMENT OF SOCIAL CAPITAL}

Can academicians, evaluators, and practitioners agree on a standard definition of social capital and its mode of operation? Can we uncover its "key ingredients?" If so, can we operationalize these key ingredients such that it is feasible to measure social capital consistently at the community level? These are not new kinds of questions. Evaluators have encountered these same dilemmas before, for example, in defining and measuring community. But this difficulty does not justify the current paucity of theoretical and practical accounts of measuring social capital. Those accounts that do exist hint at the following possible indicators: perceptions of strong help networks, community spirit, trust in civic institutions, willingness to intervene in the maintenance of public order and in the supervision of children, newspaper readership, voting rates, volunteerism, altruism, generosity, shared values, frequency of face-to-face interactions, and active membership in voluntary groups such as churches, PTA, bowling leagues, women's groups, neighborhood associations, sports clubs, and cooperatives (Baum, 1999; Durlauf, 1999; Furstenberg \& Hughes, 1995; Gardner, 1990; Kawachi, Kennedy, \& Glass, 1999; Kawachi et al., 1997; Leeder \& Dominello, 1999; Putnam, 1995, 1993; Sampson et al., 1997). 
For CPHC evaluation and measurement purposes, SRI postulates that social capital consists of both an attitudinal and a behavioral component. The attitudinal component refers to how people in a community feel and think about one another and their community, including feelings of social trust, connectedness, cooperation, and shared responsibility. For example, do community members believe that most residents can be trusted to act on each other's behalf? Do people feel that the community can work together to solve common problems? Do people feel responsible to their neighbors? The behavioral component refers to what community residents actually do and is evident at two levels: informal and formal. Informal actions include the likelihood with which community members talk and engage with each other, help each other out, report crime, and intervene on behalf of others. Formal behaviors include such things as participation in neighborhood watches, community meetings or rallies, and organizing to increase health insurance enrollment. SRI proposes that measures of these aspects of social capital be developed by using data from multiple sources, including key informant interviews, observations of behavior in public spaces, focus groups, and existing community databases. It is important that measures are made at the community level. For example, rather than aggregating individuals' personal attitudes and behaviors, I suggest that we interview key informants to learn the extent to which they feel residents in their community, as a group, hold the attitudes or demonstrate the behaviors being measured. Key informant responses would be aggregated after being scored using a rubric.

SRI recognizes that there are measurement challenges related to this conceptualization of social capital. Community attitudes are difficult to assess, and they do not equal the sum of individual residents' attitudes. SRI also recognizes that many of the behavioral components of social capital may take place in private spaces. Also, the attitudes and behaviors that best indicate social capital may vary between communities and ethnic groups within communities. Furthermore, SRI recognizes that baseline measures of social capital should have been recorded earlier in the initiative. These challenges notwithstanding, SRI believes that it is possible to develop measures that will allow examination of the linkages in the CPHC theory of change and hopes to have the opportunity to put those measures to test.

If public attention to the role of social capital in CCIs, its impact on health, and its possible value in evaluation is to be advanced, more efforts are needed to improve the theories, methods, and measurement tools used in its study. I invite other evaluators, practitioners, and academicians to join SRI in this inquiry. Unpacking and reducing social capital to measurable, knowable, and buildable elements may serve us well in discerning effective ways of steering communities toward better health (Leeder \& Dominello, 1999). Research from evaluations such as CPHC's can translate the knowledge of communities and document the diverse ways in which community interventions and strategies affect social capital and ultimately health outcomes. Certainly, something is going on out there in people's day-to-day relationships that is an important determinant of the quality of their lives and the health of their communities (Labonte, 1999). This something is helping communities to mobilize resources, think critically, access opportunity networks, and build their own organizations in ways that nurture their own trust, caring, and reciprocity (Labonte, 1999). If this something is defined as social capital, is objectively measured, and is proven to relate to health status, then the effectiveness of communities in fulfilling the goal of improving the health and well-being of children can better be ascertained in the short-term. CPHC may be producing evidence that there is a different way to go about achieving and measuring long-term community health outcomes - that the community creates the solution through the production of social capital. 


\section{ACKNOWLEDGMENTS}

The author wishes to acknowledge the contributions of members of the SRI evaluation team (Kathleen Hebbeler, Stacie Cherner, and Ruth White) and the CPHC communities. The author also wishes to thank editorial reviewers for their helpful comments on an earlier draft. Paper first presented at the Annual Meeting of the Societies for Applied and Medical Anthropology. Funding for this project was provided by SRI and the Sierra Health Foundation.

\section{REFERENCES}

Baum, F. (1999). Social capital: Is it good for your health? Issues for a public health agenda. Journal of Epidemiology and Community Health, 53, 195-196.

Bowles, S. (1999). Social capital and community governance. Focus, 20, 6-10.

Brendo, L. (1994). Reclaiming high-risk youth. In J. Becker(Ed.), Mentoring high-risk kids. Minneapolis, MN: The Johnson Foundation.

Brown, P. (1996). Comprehensive neighborhood-based initiatives. Cityscape: A Journal of Policy Development and Research, 2, 161-176.

Coleman, J. (1990). The foundations of social theory. Cambridge, MA: Harvard University Press.

Connell, J., Kubisch, A., Schorr, L., \& Weiss, C. (Eds.). (1995). New approaches to evaluating community initiatives: Concepts, methods, and contexts. Washington, DC: The Aspen Institute.

Durlauf, S. (1999). The case against social capital. Focus, 20(3), 1-5.

Easterling, D., Gallagher, K., Drisko, J., \& Johnson, T. (1998). Promoting health by building community capacity. Aspen, CO: The Colorado Trust.

Furstenberg, F., \& Hughes, M. (1995). Social capital and successful development among at-risk youth. Journal of Marriage and the Family, 57, 580-592.

Gardner, J. (1990). On leadership. New York, NY: The Free Press.

Kawachi, I., Kennedy, B., Lochner, K., \& Prothrow-Smith, D. (1997). Social capital, income inequality and mortality. American Journal of Public Health, 87, 1491-1498.

Kawachi, I., Kennedy, B., \& Glass, R. (1999). Social capital and self-rated health: A contextual analysis. American Journal of Public Health, 89, 1187-1193.

Kreuter, M. (1998). Is social capital a mediating structure for effective community-based health promotion? Working paper, Health 2000. Atlanta, GA. (Cited in Easterling et al., 1998).

Labonte, R. (1999). Social capital and community development: Practitioner emptor. Australian and New Zealand Journal of Public Health, 23, 430-433.

Lappe, F. M., \& DuBois, P. M. (1997). Building social capital without looking backward. National Civic Review, 86, 119-128.

LaVeist, T. (1992). The political empowerment and health status of African-Americans: Making a new territory. American Journal of Sociology, 116, 264-375.

Leeder, S., \& Dominello, A. (1999). Social capital and its relevance to health and family policy. Australian and New Zealand Journal of Public Health, 23, 424-429.

Putnam, R. (1993). The prosperous community: Social capital and public life. The American Prospect, $13,35-42$.

Putnam, R. (1995). Bowling alone: America's declining social capital. Journal of Democracy, 6, 65-78.

Roberts, E. (1997). Neighborhood social environments and the distribution of low birth weight in Chicago. American Journal of Public Health, 87, 597-603.

Runyan, D., Hunter, W., Socolar, R., Amaya-Jackson, L., English, D., Landsverk, J., Dubowitz, H., Browne, D., Bangdiwala, S., \& Mathew, R. (1998). Children who prosper in unfavorable environments: The relationship to social capital. Pediatrics, 101, 12-18.

Sampson, R., Raudenbush, S., \& Earls, F. (1997). Neighborhood and violent crime: A multilevel study of collective efficacy. Science, 227(15), 918-924. 
Substance Abuse and Mental Health Services Administration (2001). Prevention works through community partnerships: The community partnership program and the 48-community study. Available: http://www.health.org/govstudy/ms666/q\&a.htm.

Walsh, J. (1997). Community building in theory and practice: Three case studies. National Civic Review, $86,291-314$.

Weiss, C. H. (1995). Nothing as practical as good theory: Exploring theory-based evaluation for comprehensive community initiatives for children and families. In J. P. Connell, A. C. Kubisch, L. B. Schorr, \& C. H. Weiss (Eds.), New approaches to evaluating community initiatives: concepts, methods, and contexts. Washington, DC: The Aspen Institute. 